Елена Гришина, Елена Цаиура

\title{
ПРОБЛЕМЫ РАЗВИТИЯ НЕКОММЕРЧЕСКОГО СЕКТОРА СОЦИАЛЬНОГО ОБСЛУЖИВАНИЯ ПОЖИЛЫХ
}

\begin{abstract}
Согласно теории непрямого государственного управления, задача повышения эффективности социального обслуживания людей старшего возраста обуславливает необходимость развития некоммерческого сектора, а также межсекторного партнерства государства и НКО в данной сфере. Целью настоящей статьи является изучение институциальных барьеров и возможностей для развития некоммерческого сектора социального обслуживания пожилых граждан в России. Проводится анализ взаимодействия между некоммерческими организациями и государством, организациями внутри негосударственного сектора, кадровых проблем, проблем нормативно-правового обеспечения и налоговой нагрузки. На основе анализа суждений представителей некоммерческого сектора делаются выводы о том, какая поддержка со стороны государства может способствовать развитию негосударственных поставщиков в целом и некоммерческих поставщиков соответствующих услуг в частности. Основой для проведения анализа стали результаты интервью с 43 представителями негосударственных организаций, оказывающих услуги стационарного и надомного социального обслуживания пожилым. Для проведения исследования выбраны восемь регионов, в которых находятся столицы федеральных округов. Таким образом, выборка охватывает все федеральные округа РФ. В ходе анализа выделены основные барьеры развития изучаемого сектора: слабая заинтересованность региональных органов власти, низкий уровень взаимодействия внутри сектора, кадровые и имущественные проблемы, налоговая нагрузка. НКО могут быть партнерами государства, успешно справляясь с функциями поставщиков
\end{abstract}

Елена Евгеньевна Гришина- к.э.н., в.н.с., руководитель направления «Уровень жизни и социальная защита», Институт социального анализа и прогнозирования, РАНХиГС, Москва, Россия. Электронная почта: grishina@ranepa.ru

Елена Алексеевна Цацура-к.с.н., ст.н.с., Институт социального анализа и прогнозирования, РАНХиГС, Москва, Россия. Электронная почта: tsatsura-ea@ranepa.ru 
социальных услуг, но проведенное исследование показывает, что для развития сектора нужен ряд шагов со стороны государства. В частности, введение сертификатов в сфере социального обслуживания, обеспечение доступа к обучению персонала новым профессиональным стандартам, финансовая поддержка для приведения зданий в требуемое нормативами состояние для оказания стационарного социального обслуживания, включение негосударственных поставщиков в систему межведомственного взаимодействия, предоставление налоговых льгот. На основе результатов исследования предложены рекомендации для органов власти по развитию негосударственного сектора социального обслуживания.

Ключевые слова: НКО, система долговременного ухода, социальное обслуживание пожилых, негосударственный поставщик социальных услуг

DOI: $10.17323 / 727-0634-2020-18-3-395-410$

Теория «непрямого государственного управления» (New Governance Theory) предполагает, что для повышения эффективности социального обслуживания населения необходимо межсекторное партнерство государства и НКО (Salamon 1987; Salamon, Toepler 2015). Она изучает особенности взаимодействия государства и НКО, механизмы и инструменты, обеспечивающие реализацию этого взаимодействия. Отмечается, что увеличение производства общественных благ за счет развития некоммерческого сектора является более экономически эффективным, чем расширение производства общественных благ при помощи развития сети государственных учреждений.

В большинстве европейских стран уход за лицами старшего возраста обеспечивается за счет усилий многих сторон, включая государственные, некоммерческие и коммерческие организации (Najam 2000; Longo, Darbieri 2013; Краснопольская, Мерсиянова 2015). В зарубежной литературе отмечают, что за бурным ростом негосударственного сектора поставщиков социальных услуг стоят как относительные преимущества самих негосударственных поставщиков (Salamon, Anheir 1996), так и особые отношения, которые возникают между государством и негосударственными поставщиками (Najam 2000). В частности, в теории «непрямого государственного управления» выделяется ряд преимуществ НКО в роли поставщиков социальных услуг: гибкость деятельности, способность привлекать дополнительные ресурсы, устойчивость в условиях сокращения государственного финансирования, комплексный подход, учет индивидуальных особенностей каждого получателя услуг (Salamon, Toepler 2015). Развитие сектора негосударственных услуг по уходу позволяет улучшить их качество и доступность, дает возможность повысить эффективность расходования бюджетных средств (Schmid 2003; Chon 2018; Петренко и др. 2016). Кроме того, расширение рынка поставщиков социальных услуг 
позволяет облегчить положение лиц, осуществляющих родственный уход и увеличить их экономическую активность (Малева, Овчарова 2010). При этом передача оказания услуг негосударственным поставщикам зачастую сопровождается усилением работы по регулированию отчетности, включая разработку четких стандартов качества услуг, и процессов контроля предоставления услуг (Malley, Fernández 2010).

Данные преимущества характерны и для российских НКО (Мерсиянова, Беневоленский 2016), хотя отмечаются и слабые стороны, характерные для них как в других странах, так и в России- финансовая неустойчивость в условиях работы с временными заделами между оказанием услуги и получением возмещения из бюджета (Мерсиянова, Беневоленский 2017). Исследователи отмечают условия, необходимые для успешного сотрудничества между негосударственными поставщиками и государством. Прежде всего, это желание и способность государственных органов работать с НКО (Moran 2006; Brinkerhoff 2002), взаимное уважение и доверие, признание сильных сторон, благоприятная законодательная и регуляторная политика, эффективные механизмы мониторинга и оценки, прозрачность и подотчетность, вовлечение заинтересованных лиц на каждом этапе (Ullah et al. 2006).

В России право негосударственных поставщиков оказывать услуги социального обслуживания наравне с государственными учреждениями закреплено законом «Об основах социального обслуживания граждан в Российской Федерации» (Федеральный закон 2013). В 2016 г. принят комплекс мер и дорожная карта, направленные на обеспечение доступа негосударственных организаций к предоставлению услуг в социальной сфере. Отметим, что хотя процесс вовлечения СО НКО в оказание услуг социального обслуживания за счет бюджетных средств начат, его динамика достаточно низкая (Заболотная, Ларионов 2017; Salamon et al. 2015). Исследования показывают, что на сегодняшний день в России существует ряд факторов, сдерживающих развитие сектора негосударственных услуг по уходу. В совершенствовании нуждаются нормативно-правовое регулирование и механизмы управления. Кроме того, социальная работа с гражданами старшего возраста обладает меньшей гибкостью по сравнению с социальными услугами в других областях (Саралиева, Петрова 2018). У государственных учреждений есть ряд конкурентных преимуществ, основанных на продолжительном опыте работы и стабильном финансировании (Климова 2017). В качестве барьеров вхождения НКО на рынок социальных услуг выделяют сложность процедур вступления, отсутствие методической поддержки и диалога с органами власти, высокие административные издержки, низкие тарифы, отсутствие свободных средств для работы по схеме возмещения затрат. Кроме того, став негосударственным поставщиком социальных услуг, организации сталкиваются с проблемами нехватки информации, забюрократизированностью, 
невыплатами компенсаций и отсутствием возмещения расходов (Заболотная, Ларионов 2017; Гришина, Цацура 2019).

В продолжение исследований в области межсекторного партнерства и разгосударствления социального обслуживания, в статье изучаются институциальные барьеры и возможности для развития некоммерческого сектора социального обслуживания пожилых граждан. Проводится анализ взаимодействия между некоммерческими организациями и государством, внутри негосударственного сектора. В фокусе нашего внимания кадровые проблемы, нормативно-правовое обеспечение и налоговая нагрузка. Мы пытаемся ответить на вопрос, какая поддержка со стороны государства может способствовать развитию сектора негосударственных поставщиков в целом и некоммерческих поставщиков в частности.

\section{Методы исследования}

В 2019 г. проведено 43 интервью с представителями негосударственных организаций, оказывающих социальные услуги пожилым гражданам, в том числе 26 интервью с представителями НКО различных правовых форм (фонды, автономные некоммерческие организации, региональные общественные организации), занимающихся надомным патронажем пожилых, стационарным и полустационарным обслуживанием. Интервью проводились в восьми регионах: Московской, Нижегородской, Ростовской, Свердловской, Ленинградской, Новосибирской областях, а также Хабаровском и Ставропольском краях. Выбраны регионы, в которых находятся столицы федеральных округов, таким образом, выборка охватывает все федеральные округа. Отбор организаций для участия в исследовании производился на основе реестров поставщиков социальных услуг, по кодам ОКВЭД, поиска информации в Интернете, а также методом снежного кома. Среди охваченных опросом НКО 15 входят в реестры поставщиков социальных услуг, 12 предоставляют услуги стационарного социального обслуживания, 11 - услуги надомного обслуживания, а также девять организаций ведут различную полустационарную работу. Кроме того, дополнительно проведены десять интервью с представителями организаций-лидеров в сфере социального обслуживания, в том числе с пятью представителями некоммерческого сектора, работающими в Москве, Санкт-Петербурге и ряде других регионов.

Подчеркнем, что некоммерческий сектор в сфере ухода за пожилыми гражданами представлен организациями, оказывающими только бесплатные услуги, платные и бесплатные услуги, а также только платные услуги. Часть из охваченных обследованием организаций имели несколько источников финансирования - гранты, пожертвования, компенсации от государства за предоставленные социальные услуги, некоторые- один из перечисленных источников. Бо́льшая часть интервью проводилась по телефону, несколько 
интервью с экспертами в Москве проведены лично. Записи транскрибированы. Анализ проводился с использованием программы MAXQDA. Ниже обобщаются основные темы, поднятые информантами.

\section{Основные барьеры развития сектора некоммерческого социального обслуживания пожилых}

\section{Взаимодействие нко \\ с органами власти и государственными учреждениями}

Отсутствие заинтересованности органов власти в деятельности НКОосновная проблема в тех регионах, где развитие сектора негосударственных поставщиков слабое. Нет открытости и диалога с теми, кто хочет стать поставщиком социальных услуг. Механизмы постоянного взаимодействия организаций с органами власти не налажены, несмотря на то что периодически проводятся круглые столы, действуют экспертные общественные советы. Там, где есть НКО, работающие как ресурсные центры, ситуация лучше- у организаций появляется источник информации, а у самих ресурсных центров более тесные связи с сотрудниками министерств, есть возможность консультироваться, быстро получать необходимую информацию. Острыми проблемами являются жесткие требования к отчетности, слабое взаимодействие с государственными структурами в сфере поликлинического обслуживания, взаимное перенаправление получателей услуг. Как отмечают интервьюируемые, голос негосударственных организаций не слышат, озвучиваемые проблемы с тарифами и с отчетностью обещают решить, но ситуация никак не меняется.

В то же время в регионах, где есть развитый сектор НКО, их общение с органами власти оценивается позитивно. Например, в Ленинградской области на уровне Комитета по социальной защите создана коллегия, в которую входят представители органов власти, и представители государственных и негосударственных поставщиков социальных услуг. Организации-поставщики социальных услуг в рабочем порядке взаимодействуют с медицинскими учреждениями, пенсионным фондом, бюро МСЭ, полицией, паспортными столами. Практикуется взаимное перенаправление для решения вопросов обращающихся людей. В Ростовской области налажено взаимодействие упомянутых контрагентов и больниц, прокуратуры, участковых полицейских, библиотек, музыкальных школ и др. В Свердловской области несколько организаций отметили взаимодействие с центрами социального обслуживания, в том числе совместные благотворительные проекты и помещение в негосударственный стационар пожилых людей, которых надо срочно куда-то устроить на период ожидания места в государственном доме-интернате. В Москве взаимодействие между государственными учреждениями и НКО налажено на низовом уровне. Этому 
способствует работа Департамента социальной защиты населения, существование общественных советов, постоянное вовлечение представителей организаций в принятие решений. В Новосибирской области ряд организаций, работающих с бездомными людьми, в том числе пожилыми, достаточно тесно взаимодействует с государственными органами и особенно учреждениями социальной защиты районов, полицией, больницами. Администрация больниц обращается к НКО с просьбами помочь в работе с нуждающимися, забрать бездомных людей с улицы или после выписки из учреждения. Таким образом, работа НКО заполняет те пробелы, которые существуют в государственной поддержке населения.

В регионах пионеры из числа негосударственных организаций в первое время сталкиваются с недоверием со стороны местных властей. Их воспринимают как «чужих», они сталкиваются с непониманием преимуществ расширения состава поставщиков социальных услуг (мобильность и скорость в оказании необходимых услуг, гибкость и возможность подстраиваться под индивидуальные нужды людей, возможность поиска дополнительных средств). На уровне практической деятельности негосударственные поставщики не встроены в систему межведомственного взаимодействия и электронного документооборота, что существенным образом осложняет работу. В нескольких организациях подчеркнули, что человеческий фактор играет большую роль при выстраивании взаимодействия, преодолении первичного недоверия, закрепления личных связей. Требуется время и усилия, чтобы наладить сотрудничество. Респонденты говорили о том, что региональные власти пытаются сохранить монополию на предоставление социального обслуживания, но ясные сигналы с федерального уровня постепенно изменяют это отношение.

Услуги социального обслуживания входят в перечень общественно полезных услуг, утвержденный законодательством. Поэтому кроме реестра поставщиков социальных услуг с 2017 г. НКО, отвечающие определенным требованиям по качеству предоставляемых услуг, могут быть включены в реестр исполнителей общественно полезных услуг. Такие организации наделяются правом приоритетного получения мер поддержки. В отличие от реестров поставщиков социальных услуг, формирующихся на региональном уровне, данный реестр является федеральным. Интервью с представителями $\mathrm{HКO} \mathrm{в} \mathrm{охваченных} \mathrm{исследованием} \mathrm{регионах} \mathrm{показали,} \mathrm{что}$ такой инструмент, как реестр исполнителей общественно полезных услуг, не работает. Кто-то из представителей некоммерческого сектора даже не слышал о нем, другие тщетно пытались найти подробности про возможности, которые дает реестр и условия вступления, третьи поняли, что никаких преимуществ нахождение в данном реестре не дает. Ожидания, что включение в реестр предоставит возможность получить дополнительные виды поддержки, в том числе имущественное сопровождение, юридическое, информационное не оправдались. На уровне регионов данный статус не дает никаких преимуществ, большее значение имеет нахождение в реестре по- 
ставщиков социальных услуг. Однако нахождение и в этом реестре не всегда позволяет получить необходимую поддержку. Например, при работе с бездомными людьми, лишь часть получателей услуг, которым полностью были восстановлены документы, могут быть официально оформлены в качестве нуждающихся в получении социального обслуживания. Только наличие документов, подтверждающих личность, позволяет НКО претендовать на возмещение затрат. С остальными своими подопечными организации продолжают работать за счет собственных ресурсов.

Проведенный анализ показывает, что необходимы дополнительные усилия со стороны федеральной и региональных органов власти для налаживания взаимодействия между ними и НКО. Улучшению взаимодействия могли бы способствовать меры по разработке на федеральном уровне дополнительных методических рекомендаций, касающихся различных аспектов взаимодействия с НКО, а также создание детализированной схемы стимулирования регионов и государственных учреждений, способствующей налаживанию взаимодействия с НКО по различным направлениям.

\section{Взаимодействие между негосударственными организациями}

Внутри некоммерческого сектора долговременного ухода взаимодействие, как правило, налажено. Представители организаций общаются, обмениваются опытом, устраивают совместные мероприятия и реализуют совместные проекты. Для региональных НКО фактором, ограничивающим возможности общения с другими организациями, зачастую становится то, что других похожих организаций в регионе может не быть, а межсекторное взаимодействие находится или на очень слабом уровне или отсутствует вовсе. То есть некоммерческие и коммерческие организации, оказывающие социальное обслуживание пожилым людям, между собой могут не общаться.

В некоммерческой среде взаимодействие с бизнесом воспринимается в контексте благотворительного участия бизнеса в инициативах НКО, а не как взаимодействие партнеров по сектору долговременного ухода. В отличие от некоммерческого сектора, внутри коммерческого сектора взаимодействие организовано хуже, хотя во многом ситуация зависит от региона. Например, в Москве взаимодействие оценивается хорошо. В этой ситуации государство могло бы стать организатором площадок для обмена лучшими практиками между представителями региональных государственных организаций, НКО и коммерческих организаций в сфере социального обслуживания пожилых. Стимулирование межсекторного взаимодействия могло бы способствовать развитию сферы негосударственного социального обслуживания.

\section{Кадровые проблемы}

Кадровые проблемы- лидирующее ограничение для развития НКО в сфере социального обслуживания пожилых. Во всех охваченных регионах 
респонденты отмечали нехватку кадров, так как далеко не все готовы работать в этой сфере, выполнять непрестижную работу с должной ответственностью и пониманием своей социальной миссии. Работа с пожилыми сложна, а обеспечить условия для восстановления и профилактики выгорания организациям не хватает средств. Респонденты отметили, что зачастую работа в сфере ухода рассматривается как временная занятость. Кроме того, в НКО отмечается проблема перетекания кадров из одной организации в другую, выигравшую президентский грант.

Один из руководителей некоммерческой организации особо подчеркнул проблему низкой квалификации сотрудников в некоммерческом секторе в целом. Руководителям не хватает образования и навыков управления. Отсутствие в штате организации нужных специалистов ограничивает возможности развития. У организаций нет возможности иметь в штате аналитиков, пиар службу и других специалистов, чья работа важна для анализа и профессионального развития. Например, в одном из благотворительных фондов рассказали, что отсутствие в штате юриста не позволяет фонду запустить предоставление платных услуг.

Многие организации занимаются обучением своих сотрудников. Кто-то отмечает это как проблему, для других это возможность самим контролировать качество подготовки. Организации обучают своих сотрудников за свой счет, но не все остаются в них работать после обучения-расходы не оправдываются. Нужна государственная поддержка по обучению в рамках работы центров занятости. В таком случае на рынке бы появились профессионалы. В настоящее время еще не разработаны требования и программы обучения сиделок и помощников по уходу в соответствии с принятым стандартом. Однако во многих интервью подчеркивалась важность того, что теперь профессия официально закреплена, и работники сферы ухода могут легализоваться. Также руководители организаций отмечали, что важно предоставлять бесплатный доступ к обучению сотрудников новым технологиям наравне с сотрудниками государственных учреждений в рамках пилотных проектов по развитию системы долговременного ухода.

\section{Стандарты и требования}

Во всех регионах отмечают, что тарифы на оказание социальных услуг, позволяющих получить компенсацию из бюджета, занижены, в то время как стандарты оказания стационарных услуг- завышены. Стандарты обслуживания на дому, напротив, не обеспечивают необходимого количества и качества услуг по уходу. Мешают развитию сложности, возникающие на стыке предоставления социального обслуживания и здравоохранения.

Высокие требования к организации медицинского ухода приводят к тому, что большинство негосударственных стационаров социального обслуживания вынуждены существовать в серой зоне, чтобы не обозначать 
свою работу как медицинскую. Если организация выполнит все требования, то ее затраты приведут к очень высокой стоимости услуг, значительно выше, чем уровень платежеспособности получателей и их родственников. При этом сама сфера долговременного ухода, за исключением медицинской деятельности, регулируется слабо. У организаций, работающих в сфере ухода, нет сертификации, нет обязанности иметь специалистов, обученных по новому профессиональному стандарту.

\section{Имущество и здания}

Поиск подходящих помещений и оплата аренды- основная сложность для НКО. Нагрузка, связанная с арендой помещений, существенна для всех организаций и поэтому имущественная поддержка всегда востребована и актуальна. Даже когда здания выделяются НКО на условиях льготной аренды, организациям требуется много ресурсов и сил для самостоятельного решения всех коммунальных вопросов. Кроме того, льготная аренда не дает гарантии ее долговременности, что мешает долгосрочному планированию работы НКО.

Развитие организаций стационарного социального обслуживания сдерживается строгими требованиями и нормативами, строительными и санитарными правилами (например, запрет на размещение немобильных получателей услуг выше второго этажа, ширина коридоров в три метра, санузел шириной четыре метра и т.п.). Соответствие этим нормам предполагает наличие большой материально-технической базы, недоступной большинству некоммерческих организаций. Поэтому в регионах мало некоммерческих стационаров, а частные дома-интернаты не сотрудничают с государством и не становятся поставщиками социальных услуг, чтобы не привлекать внимание к своей деятельности. Сегодня органы власти только проверяют на соответствие требованиям, но не предлагают механизмы поддержки, которые бы позволили привести здания в необходимое состояние. Респонденты отмечали, что изменения требований в этой области приведут к стремительному развитию сектора.

\section{Налоги и налоговые льготы}

В соответствии с письмом департамента налоговой и таможенной политики Минфина (2018) пониженные тарифы страховых взносов в размере 20\% продляются на период 2019-2024 гг. для СО НКО и благотворительных организаций, применяющих упрощенную систему налогообложения. Организации, которые имеют более 100 человек в штате, теряют льготы по налогообложению даже если все их услуги для получателей бесплатны. Вместо поддержки, организация получает дополнительные расходы, которые ограничивают ее развитие. Еще одно из ограниченийнедостаточное налоговое стимулирование коммерческих предприятий к пожертвованиям. Например, при безвозмездной передаче коммерческой 
организацией товаров НКО, осуществляющей свою деятельность в соответствии с целями, указанными в ст. 2 Федерального закона (1995), у коммерческой организации не возникает обязанностей по уплате НДС (НК РФ п. 3 ст. 149). Но для того, чтобы не платить НДС, коммерческой организации необходимо иметь подтверждающие документы (Письмо... 2005). Кроме того, если безвозмездно передаваемые товары приобретены для деятельности, облагаемой НДС, то принятый к вычету НДС необходимо восстановить (НК РФ пп. 2 п. 3 ст. 170).

До 2005 г. средства, расходуемые на благотворительность, исключались из налогооблагаемой базы, что привело к развитию различных схем ухода от налогов. В связи с этим, налоговое законодательство было ужесточено и коммерческие организации могли оказывать безвозмездную помощь НКО только из средств чистой прибыли и не освобождались от уплаты налога на прибыль. Однако в 2020 г. принят Федеральный закон (2020), который предусматривает, что благотворительные пожертвования в размере не более процента от выручки можно будет отнести к внереализационным расходам в случае направления в СО НКО получателям грантов президента, субсидий и грантов федеральных, региональных и местных органов власти, исполнителям общественно полезных услуг, поставщикам социальных услуг, централизованным религиозным организациям, иным НКО, в наибольшей степени пострадавшим в условиях ухудшения ситуации в результате распространения новой коронавирусной инфекции. Указанные изменения налогового кодекса будут способствовать расширению благотворительной помощи НКО и содействовать развитию некоммерческого сектора.

\section{Заключение}

Опыт изучения межсекторного партнерства свидетельствует, что среди условий успешного сотрудничества между негосударственными поставщиками и государством важнейшее место занимает взаимная заинтересованность в сотрудничестве, уважение и признание сильных сторон друг друга, наличие разработанной нормативно-правовой базы, регулирующей данную сферу и отсутствие административных барьеров. Анализ опыта российских практик сектора негосударственного социального обслуживания показывает, что необходимые условия только начинают выстраиваться. Для развития межсекторного партнерства требуется ряд шагов, в том числе повышение эффективности взаимодействия органов государственной власти и НКО, содействие обмену опытом и распространению лучших практик работы среди НКО, содействие со стороны государства в обеспечении подготовки и повышения квалификации кадров для НКО в сфере социального обслуживания, пересмотр нормативноправовой базы, регулирующей оказание услуг, усиление имущественной и налоговой поддержки. 
В целом можно отметить, что в ближайшее время сектор негосударственного социального обслуживания будет развиваться быстрыми темпами, так как потребность в данных услугах высока и только увеличивается по причине старения населения. Однако динамика развития во многом зависит от действий государства. Теория «непрямого государственного управления〉 подчеркивает, что его роль заключается в систематизации услуг, в стандартизации и в определении квалификации работников, а также контроле за их оказанием.

Рост формального сектора социального обслуживания пожилых сдерживает низкая платежеспособность получателей услуг, особенно в небольших городах и населенных пунктах. Ситуация усложняется низкой мотивацией к сотрудничеству и диалогу со стороны органов местной власти. По этим причинам сохраняются сложности выхода новых организаций на рынок, входа в реестр поставщиков социальных услуг, проблемы низких тарифов и сложных процедур. Чиновники на местах боятся передачи услуг негосударственным поставщикам, не понимают, зачем это делать и тем самым тормозят развитие сектора. Поскольку развитие рынка во многих регионах началось недавно, первыми на него пришли энтузиасты, не всегда обладающие юридической и финансовой грамотностью, знанием бюрократических процедур для взаимодействия с органами государственной власти.

Благодаря внесенным изменениям в налоговый кодекс, созданы условия для расширения благотворительной помощи НКО и развития некоммерческого сектора. Министерство труда и социальной защиты в сотрудничестве с НКО «Старость в радость» запустило в 2018 г. пилотный проект по развитию системы долговременного ухода (СДУ), который вошел в национальный проект «Демография». Фактически НКО является его главным разработчиком и администратором, он затрагивает в 2019 г. уже более 30 регионов страны (12 в рамках плана нацпроекта и остальные по собственной инициативе регионов). Это говорит о признании государством высокой значимости некоммерческого сектора в сфере социального обслуживания. Однако для развития некоммерческого сектора очень важно, чтобы на государственном уровне НКО воспринимались как равноправные партнеры на рынке ухода, и их интересы учитывались, как при создании нормативно-правовой базы, так и при принятии ключевых решений по развитию сферы ухода.

\section{Выражение признательности}

Статья подготовлена в рамках выполнения научно-исследовательской работы государственного задания РАНХиГС.

\section{Список источников}

Гришина Е., Цацура Е. (2019) Развитие негосударственных социальных услуг для пожилых: барьеры и пути их преодоления. Экономика труда, 6 (4): 1475-1490. 
Заболотная Г., Ларионов А. (2017) Региональные практики институционализации негосударственных поставщиков социальных услуг. Вопросы государственного и муниципального управления, (3): 72-87.

Климова С. (2017) Смыслы и практики разгосударствления социальных услуг. Соииологические исследования, (2): 48-56.

Краснопольская И., Мерсиянова И. (2015) Трансформация управления социальной сферой: запрос на социальные инновации. Вопросы государственного и муниципального управления, (2):29-52.

Малева Т., Овчарова Л. (2010) Рекомендации по долгосрочным и краткосрочным мерам в социальной политике. Экономическая политика, (1): 15-26.

Мерсиянова И., Беневоленский В. (2016) Преимущества НКО как поставщиков социальных услуг: апробация в российских условиях. Bопросы государственного и муниципального управления, (4): 13-20.

Мерсиянова И., Беневоленский В. (2017) НКО как поставщики социальных услуг: верификация слабых сторон. Вопросы государственного и муниципального управления, (2): $83-102$.

Петренко Е., Кот Ю., Климова С., Богомолова Е. (2016) Социальные предприниматели на рынке социальных услуг: перспективы развития. М.: Общественное мнение.

Письмо УФНС России по г. Москве (2005) Об использовании льготы, предусмотренной подпунктом 12 пункта 3 статьи 149 НК РФ, организащией, осуществляющей благотворительную деятельность в интересах третьих лии и без иели из влечения прибыли № 19-11/55153 от 02.08.2005 г.

Письмо Департамента налоговой и таможенной политики Минфина России (2018) О продлении до 2025 г. в отношении некоммерческих и благотворительных организачий, а также субъектов малого и среднего предпринимательства, занятых в соииальной и производственной сферах, действия пониженных тарифов страховых взносов № 03-15-06/54260 от 1.08.2018 г.

Саралиева 3., Петрова И. (2018) Пожилые в российской негосударственной социальной работе. Журнал исследований социальной политики, 16 (1):95-108.

Федеральный закон (1995) О благотворительной деятельности и добровольчестве (волонтерстве) № 135-ФЗ от 11.08.1995 г.

Федеральный закон (2000) Налоговый кодекс РФ, часть 2 № 117-Ф3 от 5.08.2000 г.

Федеральный закон (2013) Об основах сочиального обслуживания граждан в Российской Федеращии № 442-ФЗ от 28.12.2013 г.

Федеральный закон (2020) О внесении изменений в часть вторую Налогового кодекса Российской Федераџии № 172-ФЗ от 8.06.2020 г.

Brinkerhoff J. (2002) Government-nonprofit Partnership: A Defining Framework. Public Administration and Development, 22 (1): 19-30.

Chon Y. (2018) The Effects of Marketization of Long-term Care Services for Older Adults in Korea. Journal of Social Service Research, 45 (4): 507-519. 
Longo F., Barbieri D. (2013) Using Relational and Transactional MCSs to Manage the Delivery of Outsourced Public Services: Evidence from Twelve Cases in the USA. Financial Accountability \& Management, 29 (1): 50-73.

Malley J., Fernández J. (2010) Measuring Quality in Social Care Services: Theory and Practice. Annals of Public and Cooperative Economics, 81 (4):559-582.

Moran D. (2006) Comparing Services: A Survey of Leading Issues in the Sectoral Literature. Public Administration and Development, 26 (3): 197-206.

Najam A. (2000) The Four C's of Third Sector- Government Relations: Cooperation, Confrontation, Complementarity and Co-optation. Nonprofit Management and Leadership, 10 (4): 375-396.

Salamon L.M. (1987) Partners in Public Service: The scope and theory of government nonprofit relations. In: W. Powell (ed.) The Nonprofit Sector: A Research Handbook. New Haven: Yale University Press.

Salamon L., Anheier H. (1996) The Emerging Nonprofit Sector: An Overview. Manchester: Manchester University Press.

Salamon L., Toepler S. (2015) Government-Nonprofit Cooperation: Anomaly or Necessity? VOLUNTAS: International Journal of Voluntary and Nonprofit Organizations, (26): 2155-2177.

Salamon L., Benevolenski V., Jakobson L. (2015) Penetrating the Dual Realities of Government-Nonprofit Relations in Russia. VOLUNTAS: International Journal of Voluntary and Nonprofit Organizations, 26 (6): 2178-2214.

Schmid H. (2003) Rethinking the Policy of Contracting Out Social Services to Non-governmental Organizations: Lessons and Dilemmas. Public Management Review, (3):307-323.

Ullah A., Newell J., Ahmed J., Hyder M., Islam A. (2006) Government-NGO Collaboration: The Case of Tuberculosis Control in Bangladesh. Health Policy and Planning, 21 (2): 143-55. 
Elena Grishina, Elena Tsatsura

\title{
PROBLEMS OF DEVELOPMENT IN THE NON-PROFIT SECTOR OF SOCIAL SERVICES FOR THE ELDERLY
}

\begin{abstract}
According to New Governance Theory, the task of increasing the efficiency of social services for older people requires the development of a non-profit sector of social services, as well as an intersectoral collaboration in this area. The purpose of this article is to study the institutional barriers and opportunities for the development of the non-profit sector of social services for senior citizens. The analysis was based on forty-three interviews with representatives of non-governmental organizations providing stationary and home-based social services for the elderly. For the study, eight regions were selected in which the capitals of the federal districts are located. Thus, the sample covers all federal districts of the Russian Federation. During the analysis, the main barriers to the development of the sector were identified: low interest on the part of the regional authorities, low level of interaction within the sector, personnel and property problems, and the tax burden. NPOs can be partners of the state, successfully coping with the functions of social service providers, but the study shows that the development of the sector requires a number of additional steps on the part of the state. In particular, this includes the introduction of certificates in the field of social services, providing access to staff training in new professional standards, financial support for bringing buildings to the required state for in-patient social services, the inclusion of non-state providers in the system of interagency cooperation, and the provision of tax benefits. Based on the results of the study, recommendations are made for the authorities on the development of the non-governmental sector of social services.
\end{abstract}

Key words: NGO, long term care, LTC, social care for the elderly, nongovernment providers

DOI: 10.17323/727-0634-2020-18-3-395-410

\section{References}

Brinkerhoff J. (2002) Government-nonprofit Partnership: A Defining Framework. Public Administration and Development, 22 (1): 19-30.

Chon Y. (2018) The Effects of Marketization of Long-term Care Services for Older Adults in Korea. Journal of Social Service Research, 45 (4): 507-519.

Elena Grishina-Cand. Sci. (Econ.), Leading Researcher, Institute for Social Analysis and Prediction, RANEPA, Moscow, Russian Federation. Email: grishina@ranepa.ru

Elena Tsatsura-Cand. Sci. (Soc.), Senior Researcher, Institute for Social Analysis and Prediction, RANEPA, Moscow, Russian Federation. Email: tsatsura-ea@ranepa.ru 
Federal Law (1995) O blagotvoritel'noy deyatel'nosti i dobrovol'chestve (volonterstve) [About Charity and Volunteering (volunteering)] No. 135-FZ from 11.08.1995.

Federal Law (2000) Nalogovyy kodeks RF [Tax Code of the Russian Federation] No. 117FZ from 5.08.2000.

Federal Law (2013) Ob osnovakh sotsial'nogo obsluzhivaniya grazhdan v Rossiyskoy Federatsii [On the Basics of Social Services for Citizens in the Russian Federation] No. 442FZ from 28.12.2013.

Federal Law (2020) O vnesenii izmeneniy v chast'vtoruyu Nalogovogo kodeksa Rossiyskoy Federatsii [On Amendments to Part Two of the Tax Code of the Russian Federation] No. 172-FZ from 8.06.2020.

Grishina E., Tsatsura E. (2019) Razvitiye negosudarstvennykh sotsial'nykh uslug dlya pozhilykh: bar'yery i puti ikh preodoleniya [The Development of Non-state Social Services for the Elderly: Barriers and Ways to Overcome Them]. Ekonomika truda [Labor Economics], 6 (4): 1475-1490.

Klimova S. (2017) Smysly i praktiki razgosudarstvleniya sotsial'nykh uslug [Meanings and Practices of Degovernmentalization of Social Services]. Sotsiologicheskiye issledovaniya [Sociological Research], 394 (2): 48-56.

Krasnopol'skaya I., Mersiyanova I. (2015) Transformatsiya upravleniya sotsial'noy sferoy: zapros na sotsial'nyye innovatsii [Transformation of the Social Sphere Administration: Demand for Social Innovations]. Voprosy gosudarstvennogo i munitsipal'nogo upravleniya [Public Administration Issues], (2): 29-52.

Letter of the Federal Tax Service of Russia for Moscow (2005) Ob ispol'zovanii l'goty, predusmotrennoy podpunktom 12 punkta 3 stat'i 149 NK RF, organizatsiyey, osushchestvlyayushchey blagotvoritel'nuyu deyatel'nost'v interesakh tret'ikh lits i bez tseli izvlecheniya pribyli [On the Use of the Benefit Provided for in Subparagraph 12 of Paragraph 3 of Article 149 of the Tax Code of the Russian Federation, for an Organization that Conducts Charity Work in the Interests of Third Parties and without the Purpose of Making a Profit] No. 19-11/55153 from 02.08.2005.

Letter of the Department of Tax and Customs Policy of the Ministry of Finance of Russia (2018) Ob ispol'zovanii l'goty, predusmotrennoy podpunktom 12 punkta 3 stat'i $149 \mathrm{NK}$ $R F$, organizatsiyey, osushchestvlyayushchey blagotvoritel'nuyu deyatel'nost'v interesakh tret'ikh lits $i$ bez tseli izvlecheniya pribyli [On the Extension until 2025 in Respect of Nonprofit and Charitable Organizations, as well as Small and Medium-sized Enterprises Engaged in Social and Industrial Spheres, the Effect of Reduced Insurance Premium Rates] No. 03-15-06/54260 from 1.08.2018.

Longo F., Barbieri D. (2013) Using Relational and Transactional MCSs to Manage the Delivery of Outsourced Public Services: Evidence from Twelve Cases in the USA. Financial Accountability \& Management, 29 (1): 50-73.

Maleva T., Ovcharova L. (2010) Rekomendatsii po dolgosrochnym i kratkosrochnym meram v sotsial'noy politike [Recommendations for Long-term and Short-term Interventions in Social Policy]. Ekonomicheskaya politika [Economic Policy], (1): 15-26.

Malley J, Fernández J. (2010) Measuring Quality in Social Care Services: Theory and Practice. Annals of Public and Cooperative Economics, 81 (4):559-582. 
Mersiyanova I., Benevolenskiy V. (2016) Preimushchestva NKO kak postavshchikov sotsial'nykh uslug: aprobatsiya v rossiyskikh usloviyakh [The Comparative Advantages of NPOs as Social Welfare Services Providers: An Examination in the Russian Context]. Voprosy gosudarstvennogo i munitsipal'nogo upravleniya [Public Administration Issues], (4): $13-20$.

Mersiyanova I., Benevolenskiy V. (2017) NKO kak postavshchiki sotsial'nykh uslug: verifikatsiya slabykh storon [NPOs as Social Services Providers: Organizational Weaknesses Verification]. Voprosy gosudarstvennogo i munitsipal'nogo upravleniya [Public Administration Issues], (2): 83-102.

Moran D. (2006) Comparing Services: A Survey of Leading Issues in the Sectoral Literature. Public Administration and Development, 26 (3): 197-206.

Najam A. (2000) The Four C's of Third Sector- Government Relations: Cooperation, Confrontation, Complementarity and Co-optation. Nonprofit Management and Leadership, 10 (4):375-396.

Petrenko E., Kot Yu., Klimova S., Bogomolova E. (2016) Sotsial'nyye predprinimateli na rynke sotsial'nykh uslug: perspektivy razvitiya [Social Entrepreneurs on the Market of Social Services: Prospects Of Development]. Moscow: Obshchestvennoye mneniye.

Salamon L. M. (1987) Partners in Public Service: The Scope and Theory of Government Nonprofit Relations. In: W. Powell (ed.) The Nonprofit Sector: A Research Handbook. New Haven: Yale University Press.

Salamon L., Anheier H. (1996) The Emerging Nonprofit Sector: An Overview. Manchester: Manchester University Press.

Salamon L., Toepler S. (2015) Government-Nonprofit Cooperation: Anomaly or Necessity? VOLUNTAS: International Journal of Voluntary and Nonprofit Organizations, (26):2155-2177.

Salamon L., Benevolenski V., Jakobson L. (2015) Penetrating the Dual Realities of Government-Nonprofit Relations in Russia. VOLUNTAS: International Journal of Voluntary and Nonprofit Organizations, 26 (6): 2178-2214.

Saraliyeva Z., Petrova I. (2018) Pozhilyye v rossiyskoy negosudarstvennoy sotsial'noy rabote [The Elderly in Russian Non-Governmental Social Work]. Zhurnal Issledovanii Sotsial'noi Politiki [The Journal of Social Policy Studies], 16 (1):95-108.

Schmid H. (2003) Rethinking the Policy of Contracting Out Social Services to Non-governmental Organizations: Lessons and Dilemmas. Public Management Review, (3):307-323.

Ullah A., Newell J., Ahmed J., Hyder M., Islam A. (2006) Government-NGO Collaboration: The Case of Tuberculosis Control in Bangladesh. Health Policy and Planning, 21 (2): $143-55$.

Zabolotnaya G., Larionov A. (2017) Regional'nyye praktiki institutsionalizatsii negosudarstvennykh postavshchikov sotsial'nykh uslug [Regional Practices in the Institutionalization of Non-Governmental Social Welfare Services' Providers]. Voprosy gosudarstvennogo i munitsipal'nogo upravleniya [Public Administration Issues], (3): $72-87$. 